
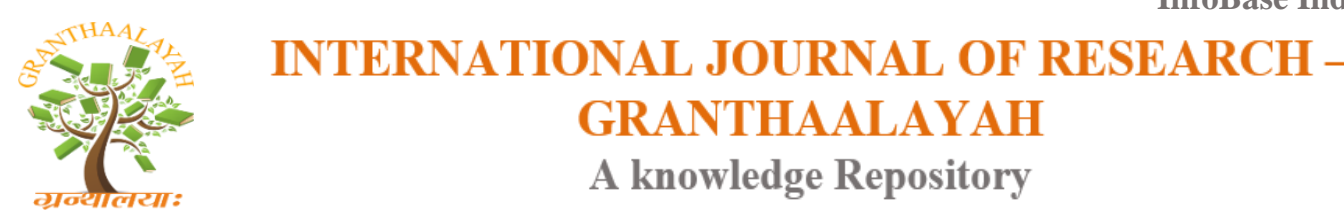

Science

\title{
VARIOUS TYPES OF SPACES PARKING AND LIGHT WEIGHT FOUR WHEELER PARKING
}

\author{
Dr.Sanjeev Gill*1, Dr. Rajeev Kumar ${ }^{2}$ \\ ${ }^{* 1,2}$ HOD, Department of Civil Engineering, JBIT, Dehradun, (U.K), India
}

DOI: https://doi.org/10.29121/granthaalayah.v5.i3.2017.1763

\begin{abstract}
The unscrupulous growing population has created many problems in country like India. Parking is one of the serious problems that confront the urban planner and the traffic engineer. One of the problems created by road traffic is parking. Not only do vehicles require street space to move about, but also do they require space to park where the occupants can be loaded and unloaded. It is roughly estimated that out of 8,760 hours in a year, the car runs on an average for only 400 hours, leaving 8,360 hours when it is parked. Besides the problem of space for cars moving on the road, greater is the problem of space for a parked vehicle considering that private vehicles remain parked for most of their time. Besides the problem of space for cars moving on the road, greater is the problem of space for a parked vehicle considering that private vehicles remain parked for most of their time. While residential projects still escape with designated parking, the real problem lies with commercial spaces many a time which is overcome by taking extra open spaces to park. Multi-level Parking systems for some time have provided relief since they come with a number of advantages - Optimal utilization of space, lower maintenance and operational cost, lower construction cost, secure and environment-friendly nature, comfortable for the drivers, cost saving for builders by saving height or depth. Multiple Level Car Parking Systems are much in vogue a method of automatically parking and retrieving cars that typically use a system of pallets and lifts and signaling devices for retrieval. They serve advantages like safety, saving of space, time and fuel space but also need to have an extra and a very detailed assessment of the parking required, space availability and traffic flow.
\end{abstract}

Keywords: Traffic; Parking; Traffic Flow; Parking Space; Degree Parking; Safety; Car Parking.

Cite This Article: Dr.Sanjeev Gill, and Dr. Rajeev Kumar. (2017). "VARIOUS TYPES OF SPACES PARKING AND LIGHT WEIGHT FOUR WHEELER PARKING." International Journal of Research - Granthaalayah, 5(3), 161-166.

\section{Introduction}

History: Over the years, car parking systems and the accompanying technologies have increased and diversified. Car parking systems have been around almost since the time cars were invented. 
In any area where there is a significant amount of traffic, there are car parking systems. Car Parking systems were developed in the early 20th century in response to the need for storage space for vehicles. In the 1920s, forerunners of automated parking systems appeared in U.S. cities like Los Angeles, Chicago, New York City and Cincinnati. Some of these multi-stored structures are still standing, and have been adapted for new uses. One of the Kent Automatic Parking Garages in New York (now known as the Sofia Apartments) is an Art Deco landmark that was converted into luxury condominiums in 1983. A system that is now found all over Japan — the "Ferris-wheel," or paternoster system - was created by the Westinghouse Corporation in 1923 and subsequently built in 1932 on Chicago's Monroe Street. The Nash Motor Company created the first glass-enclosed version of this system for the Chicago Century of Progress Exhibition in 1933, and it was the precursor to a more recent version, the Smart Car Towers in Europe.

\section{Parking}

Traffic engineering is that branch of engineering which deals with the improvement of traffic performance of road networks and terminals. Parking is one of the serious problems that confront the urban planner and the traffic engineer. Each category of vehicular traffic has two components, the human element as the driver and his machine as vehicles. Traffic engineering has now been recognized as an essential tool in the improvement of traffic operations in metropolitan cities like Bombay, Delhi, Calcutta and Madras. The growing population of India has created many problems - one of the challenging ones being car parking which we confront almost every day. Besides the problem of space for cars moving on the road, greater is the problem of space for a parked vehicle considering that private vehicles remain parked for most of their time. Roads are being built for cars to ply but are we also giving the vehicles enough space to park. Parking is one of the major problems that is created by the increasing road track. It is an impact of transport development. The availability of less space in urban areas has increased the demand for parking space especially in areas like Central business district. A systematic study of the parking characteristic and demand and regulatory measures that are possible for controlling parking is of the great help to a traffic engineer as well as a town planner.

\section{Preliminary Studies}

Before taking any measures for the betterment of conditions, data regarding availability of parking space, extent of its usage and parking demand is essential. It is also required to estimate the parking fares also. Parking surveys are intended to provide all these information. Since the duration of parking varies with different vehicles, several statistics are used to access the parking need. Its proposed to implement a system of parking charges it will be the effect of the pricing policy on parking. Parking surveys are intended to supply all this kind of information.

\section{Data-of-Parking}

- Parking accumulation - It may be defined as the number of vehicles parked at a given instant of time. The total numbers of vehicles parked in an area at a specified moment. The curve of parking accumulation for a typical day and taken as average accumulation 
normally this is expressed by accumulation curve. Accumulation curve is the graph obtained by plotting the number of bays occupied with respect to time.

- Parking volume - Parking volume is the total number of vehicles parked at a given duration of time. The number of vehicles parking in a particular area over a given period of time. This does not account for repetition of vehicles.

- Parking Load - Parking load gives the area under the accumulation curve. It can also be obtained by simply multiplying the number of vehicles occupying the parking area at each time interval with the time interval. It is expressed as vehicles per hour. The hatched area represents the parking load in vehicle-hour for a period of 4 hours from 6 AM to 10 AM.

- Average parking duration - It is the ratio of total vehicle hours to the number of vehicles parked. The length of time spent in a parking space.

- Parking Turnover - It is the ratio of number of vehicles parked in duration to the number of parking bays. This can be expressed as number of vehicles per bay per time duration. Rate of the use age of the available parking space. Thus if there were 10 parking spaces used by 100 vehicles in a period of say 12 hours, then parking turnover would be

- $\quad \mathbf{= 1 0 0 / 1 0}$ vehicles per space in a period of $\mathbf{1 2}$ hours.

- Parking index - Parking index is also called occupancy or efficiency. It is defined as the ratio of number of bays occupied in time duration to the total space available. It gives an aggregate measure of how effectively the parking space is utilized. Parking index can be found out as follows

\section{Parking index $=($ parking load/parking capacity $)$ X 100}

\section{Parking-Effects}

Parking has some effects like congestion, accidents, pollution, obstruction to fire-fighting operations etc.

Congestion- Parking takes considerable street space leading to the lowering of the road capacity. Hence, speed will be reduced; journey time and delay will also subsequently increase. The operational cost of the vehicle increases leading to great economical loss to the community.

Accidents- Careless maneuvering of parking and unparking leads to accidents which are referred to as parking accidents. Common type of parking accidents occur while driving out a car from the parking area, careless opening of the doors of parked cars, and while bringing in the vehicle to the parking lot for parking.

Environmental pollution- They also cause pollution to the environment because stopping and starting of vehicles while parking and unparking results in noise and fumes. They also aced the aesthetic beauty of the buildings because a car parked at every available space creates a feeling that building rises from a plinth of cars.

Obstruction to firefighting operations- Parked vehicles may obstruct the movement of firefighting vehicles. Sometimes they block access to hydrants and access to buildings.

\section{Type-of-Parking}

On street parking- On street parking means the vehicles are parked on the sides of the street itself. This will be usually controlled by government agencies itself. Common types of on-street 
parking are as listed below. As per IRC the Standard dimensions of a car is taken as $5 \times 2.5 \mathrm{~m}$ and that for a truck is $3.75 \times 7.5 \mathrm{~m}$.

\section{Common methods of on-street parking}
i. Parallel parking
ii. $\quad 30^{\circ}$ Angle parking
iii. $\quad 45^{\circ}$ Angle parking
iv. $\quad 60^{\circ}$ Angle parking
v. Right Angle parking

\section{Parallel Parking}

The vehicles are parked along the length of the road. Here there is no backward movement involved while parking or un parking the vehicle. Hence, it is the most safest parking from the accident perspective. However, it consumes the maximum curb length and therefore only a minimum number of vehicles can be parked for a given curbed length. This method of parking produces least obstruction to the on-going track on the road since least road width is used. The angle considered in parallel parking is $180^{\circ}$ and its also called as parallel parking.
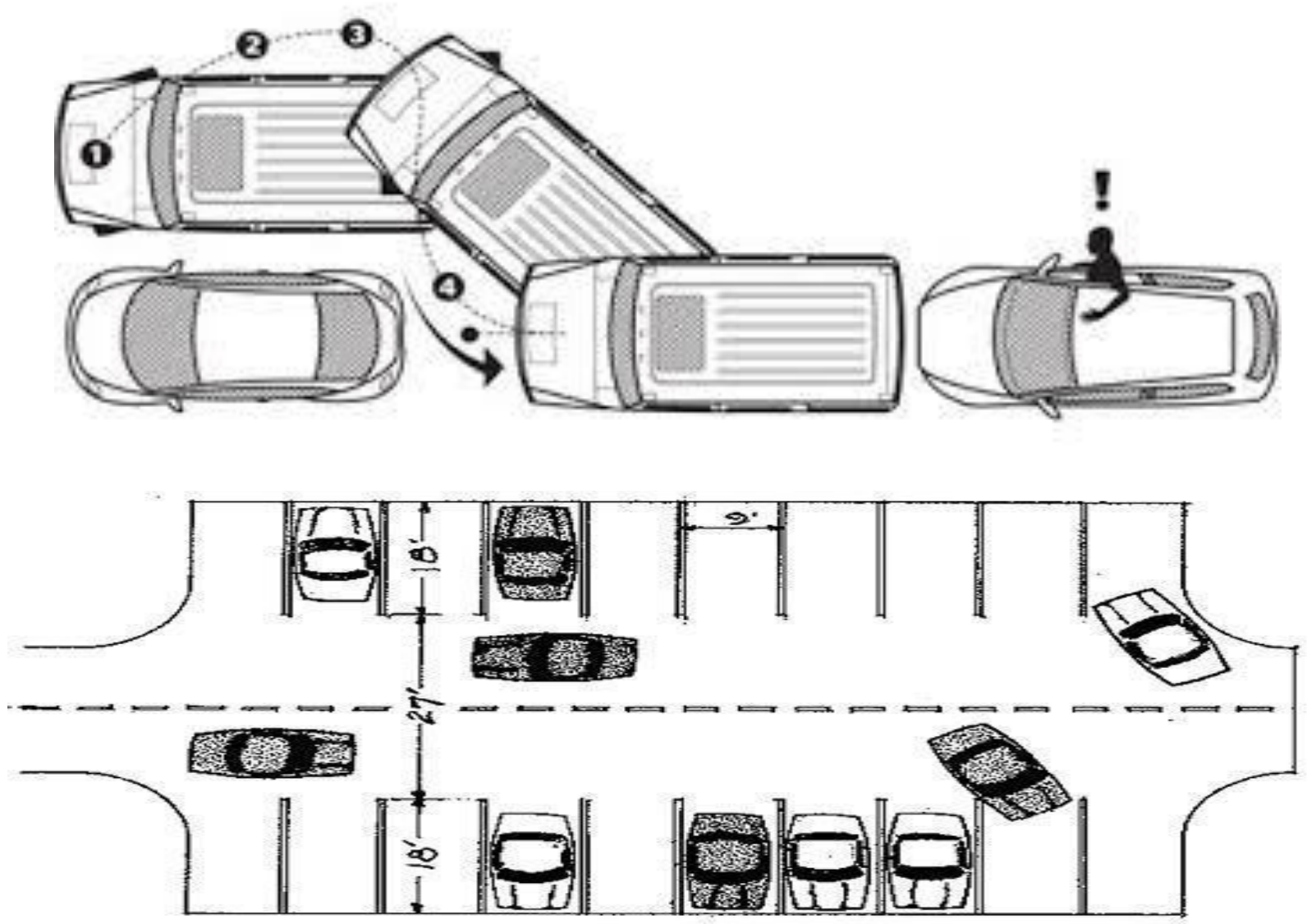
Parking 90

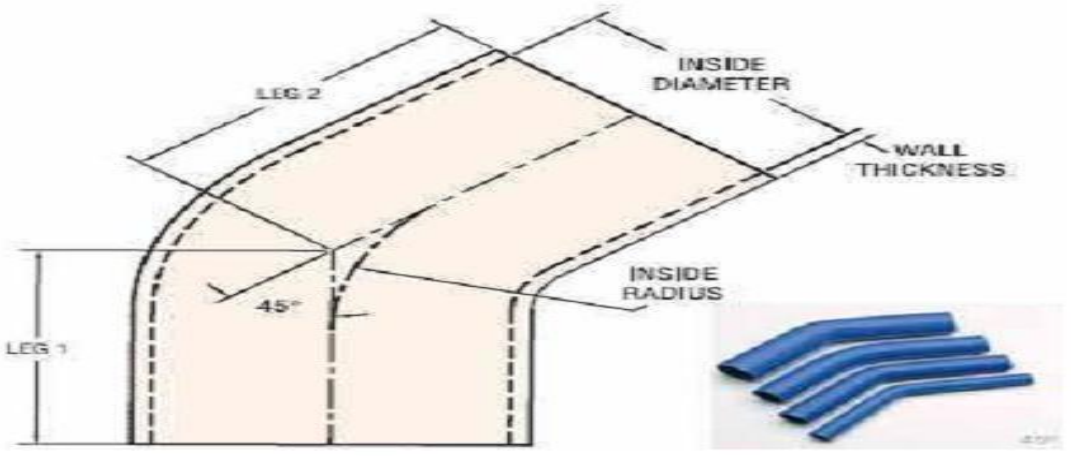

\section{Degree Parking}

\section{Necessity-of-Car-Parking}

Optimal utilization of spaces- Mechanical car parking system is a method of parking and retrieving cars by using pallets and lifts. It thus removes the need for lengthy drive ways and ramps, accommodating maximum cars in minimum space.

Can be constructed in minimum available space- It can be sited above or below the ground or a combination of both and designed to accommodate any number of cars.

Low construction cost- Parking schemes are cost effective as far as from construction point of view. As the system is operated automatically, added expenses of underground parking such as building structure, providing lighting and security are avoided.

Low maintenance and operational cost- Operating cost is low since mechanical car parking systems requires less energy to run. There is no need for energy intensive ventilating systems as the cars are not being driven inside the parking lot.

Safety of vehicle- Efficient parking pattern provide complete safety to a vehicle as parked cars are not accessible to anyone else. Damages or a dent to the car is avoided while parking through narrow drive ways.

\section{Environment friendly-}

Environmentally, mechanized car parking has much to offer. One of the greatest benefits related to conventional underground or open space parking, is the saving of ground space. Outdoor space saved can be put to good use with gardens and landscaping or additional buildings. It also significantly reduces noise.

Benefit to a driver- Car driving now can become a pleasant experience. Mechanical car parking systems makes parking easier and less stressful as the driver does not have to drive through the entire parking lot looking for a place to park, nor do they have to attend the car when it is parked, thus saving a lot of time. Difficulty in parking in a tight corner is also eliminated.

\section{Benefits}

There are several advantages of employing a car park system for urban planners, business owners and vehicle drivers. They offer convenience for vehicle users and efficient usage of space for urban-based companies. Automated car park systems save time, money, space and simplify the often tedious task of parking. Auto car lifts move vehicles into safe and secure storage areas until they are needed. 


\section{Barriers}

Parking spaces commonly contain a parking chock (wheel stop), which is used to prevent cars from pulling too far into the space and

- Obstructing a neighboring parking space, curb, or sidewalk.

- Contacting with and then damaging a building wall.

This barrier is usually made of concrete and will normally be a horizontal bar to stop the tires from moving forward or a vertical bar that may cause damage to the vehicle if contact is made. In a parking garage, the barrier will often be a concrete wall.

\section{Maintenance and Service}

Service intervals vary for automated car parking systems, depending on the type of machines used and their usage. Parking systems should be serviced at least once a year, and up to four times a year for high traffic areas or for valet parking. In addition, regular cleaning is mandatory to keep the car parking system in great working order, especially with the problems posed by weather (salt)on the road can spread to lifter platforms and cause severe damage if not removed.

\section{Road Safety Traffic}

The basic strategy of a Safe System approach is to ensure that in the event of a crash, the impact energies remain below the threshold likely to produce either death or serious injury. This threshold will vary from crash scenario to crash scenario, depending upon the level of protection offered to the road users involved.

\section{Conclusions}

Cities and other higher order cities becoming scarce and dearer and plots getting smaller conventional parking is proving infeasible. The solution for the parking requirements is the multi-level car parking system to maximize car parking capacity by utilizing vertical space, rather than expanding horizontally. The most popular choice in terms of technology preferred is automated (lift based) selected by nearly $70 \%$ of the users.

\section{References}

[1] Khanna S. K. Professor and Head, Civil Engineering Department University of Roorkee, ROORKEE

[2] Justo C.E.G. Professor, Department of Civil Engineering, Bangalore University, BANGALORE

[3] Kadiyali L.R. Chief Engineer, Ministry of Shipping and Transport, New Delhi

[4] Gupta B.L. Head of Civil Engineering Department, Standard Publication, Delhi

[5] Prashant Dixit Chief Executive Engineer, Arihant Publication, New Delhi

[6] B. Singh (Ex.IES) Founder \& Director, MADE EASY Group

*Corresponding author.

E-mail address: sanjeev_kumar_gill1@yahoo.co.in 